\title{
Makna Hijrah Dalam Tafsir Fi Zhilal Al-Qur'an Karya Sayyid Quthb
}

\author{
M Maskun Hadi \\ Universitas Islam Negeri Raden Fatah Palembang \\ m.askunhadii@gmail.com \\ Muhajirin \\ Universitas Islam Negeri Raden Fatah Palembang \\ mahanigafar1004@yahoo.com \\ Kusnadi \\ Universitas Islam Negeri Raden Fatah Palembang \\ kusnadi_uin@radenfatah.ac.id
}

\begin{abstract}
Abstrak
Tulisan ini menjelaskan makna hijrah dalam tafsir fi Zhilal al-Qur'an karya Sayyid Quthb. Dengan memakai metode deskriptif-kualitatif dan dibantu pendekatan tafsir maudhu'i, didapatkan kesimpulan bahwa makna hijrah menurut Sayyid Qutub mengandung berbagai arti, antara lain: hijrah dalam arti berpindah atau meninggalkan negeri yang mayoritas ahli bid'ah dan orang-orang kafir, meninggalkan negeri atau tempat yang dipenuhi oleh hal yang merugikan baik itu demi keselamatan jiwa, kesehatan tubuh agar terhindar dari penyakit, dan melarikan diri untuk menyelamatkan harta benda. Sayyid Quthb juga menjelaskan jenis hijrah yang bisa dilakukan pada masa sekarang, antara lain: dapat dilakukan dengan menempuh pendidikan (menuntut ilmu), perjalanan untuk menegakkan agama Allah (jihad) dan membela negara, serta perjalanan untuk menjemput rezeki.
\end{abstract}

Kata Kunci: Hijrah, Sayyid Quthb, Tafsir Fi Zhilal Al-Qur'an

\begin{abstract}
This paper explains the meaning of hijrah in Sayyid Qutb's interpretation of $f i$ Zhilal al-Qur'an. By using a descriptive-qualitative method and assisted by a maudhu'i interpretation approach, it is concluded that the meaning of hijrah according to Sayyid Qutub contains various meanings, including: hijrah in the sense of moving or leaving a country where the majority of heretics and infidels leave the country. Or a place filled with harmful things, whether it is for the safety of the soul, health of the body to avoid disease, and escape to save property. Sayyid Qutb also explained the types of hijrah that can be done today, among others: it can be done by taking education (seek knowledge), traveling to uphold Allah's religion (jihad) and defending the country, as well as traveling to pick up sustenance.
\end{abstract}

Keywords: Hijrah, Sayyid Qutb, Tafsir Fi Zhilal Al-Qur'an 


\section{PENDAHULUAN}

Perubahan yang besar pada dunia disebabkan oleh perkembangan zaman yang cepat (pesat). Tidak sekedar berbenturan pada perubahan budaya, tetapi juga tentang perubahan sosial. ${ }^{1}$ Sehingga terjadi kesenjangan sosial antara penduduk asli dengan penduduk datangan, baik dalam ekonomi maupun dalam sisi budaya. Banyaknya migrasi disebabkan perkembangan penduduk yang begitu cepat, dengan beberapa alasan baik alasan ekonomi, keamanan, politik, maupun alasan sosial. ${ }^{2}$ Dalam Kamus Besar Bahasa Indonesia, migrasi memiliki arti berpindahnya ke wilayah lain untuk bermukim (menetap). ${ }^{3}$

Salah satu representasi keimanan seseorang adalah dengan berhijrah, meninggalkan kesenangan dunia demi mencapai kesalehan dan kebahagian yang hakiki. Hijrah merupakan peristiwa penting dalam sejarah Islam. Ayat yang berbicara mengenai masalah hijrah di antaranya QS. al-Nisa [4]: 97-100. Rasyid Ridha menyebutkan sebab diperintahkannya hijrah bagi umat Islam, yaitu jika sudah tidak ada kebebasan beribadah dan menjalankan aturan agama dalam suatu negeri, serta tidak adanya juru dakwah dalam suatu negeri. Sedangkan menurut Adhim, tiga hal yang menyebabkan diperintahkannya untuk berhijrah adalah adanya perbuatan haram dan kemungkaran di sebuah wilayah, adanya penyakit yang membahayakan masyarakat, dan karena adanya keinginan menjemput rezeki di tempat yang lain. ${ }^{4}$

Dari segi literatur Sufi modern, hijrah termasuk tingkatan penting dalam perjalanan jiwa buat kembali pada Allah SWT. Hijrah diklaim bagian dari cara pembersihan diri, karena telah lapang dada menahan kesulitan-kesulitan sebagai bentuk bukti cintanya kepada Allah SWT. Secara tidak langsung, konsep hijrah masih berkaitan dengan jihad, sebagaimana dalam berhijrah manusia itu memerlukan tekad serta perjuangan luar biasa sebagai bentuk jihad. ${ }^{5}$ Tulisan ini berusaha mengungkap makna hijrah menurut mufasir modern Sayyid Quthb dalam kitab Tafsir Fi Zhilal al-Qur'an. Tujuan spesifiknya untuk mengetahui kontribusi penerapan hijrah Sayyid Qutub pada masa sekarang dalam kitab tafsirnya, untuk mengetahui makna hijrah dan juga beberapa karakteristik hijrah yang diusungnya. Selain itu, hasil dari tulisan ini diharapkan mampu memberikan wawasan baru terkait makna hijrah yang tepat dalam konteks kekinian mengingat tuntutan zaman yang terus berkembang.

${ }^{1}$ Paul B. Horton \& Chester L. Hunt, Sosiologi Jilid Dua, terj. Aminuddin Ram, cet 3 (Jakarta: Erlangga, 1992), 218.

2 Paul B. Horton \& Chester L. Hunt, Sosiologi Jilid Dua..., 103-104.

3 Poerwadiningrat, Kamus Besar Bahasa Indonesia, Edisi 3 (Jakarta: Balai Pustaka, 2005), 742.

${ }^{4}$ Ahmad Abdul Adhim Muhammad, Strategi Hijrah Prinsip-Prinsip Ilmiah dan Ilham Tuhan, terj. M. Masnur Hamzah (Solo: Tiga Serangkai, 2004), 16.

${ }^{5}$ Hamka, Tafsir Al Azhar, (Jakarta: Pustaka Panjimas, 1984), 228. 


\section{METODE PENELITIAN}

Tipe penelitian ini berbentuk kepustakaan (library research), menggunakan metode deskriptif-kualitatif dengan analisis tafsir maudhu'i. Sumber data primer yang digunakan yaitu dari kitab Tafsir Fii Zhilal Al-Qur'an karya Sayyid Quthb. Sementara data sekundernya mencakup kitab-kitab tafsir yang memuat tentang hijrah, antara lain seperti Tafsir Al Azhar, Tafsir Ibnu Katsir, Tafsir al-Mishbah, dan buku-buku penunjang lainnya yang berhubungan dengan tema pembahasan. Sedangkan teknik analisis isi (content analysis) merupakan teknik yang dipakai penulis dalam penelitian ini sehingga teks yang ada tersusun dengan rapi agar mudah dicerna dan dipahami.

\section{HASIL DAN PEMBAHASAN}

\section{Memahami Makna Hijrah}

Dalam budaya masyarakat di Indonesia, kata hijrah tidaklah asing didengar. Kata yang diserap dari bahasa Arab "hajara-yahjuru-hajran" memiliki arti 'memutuskan hubungan'.6 Kata tersebut merupakan antonim dari kata "alWasl" yang artinya menyambung. ${ }^{7}$ Kata hijrah dapat juga bermakna al-khuruj min ardila ard, yaitu pergi menuju wilayah lain. Dalam kamus al-Mawrid, Rohi Baalbaki menyatakan kata hijrah memiliki arti "to migrate, to immigrate, to emigrate, leave one's native country". 8 Sementara dalam KBBI, kata hijrah adalah berpindahnya Nabi Muhammad SAW meninggalkan kota Mekkah menuju Madinah bertujuan untuk menjauhi desakan dan paksaan dari kalangan Qurasiy. ${ }^{9}$

Menurut Ibnu Arabi, Ibnu Taymiyyah, serta Ibnu Hajar al-'Asqalani, hijrah diartikan dengan meninggalkan negeri kafir yang penuh kezaliman atau "dar alkufr wa al-harb" menuju negeri Islam atau "dar al-Islam" yang memberlakukan hukum syariat Islam. Ibn Arabi menegaskan pengertian hijrah sebagai berikut; pertama, pergi dari negeri atau wilayah orang kafir menuju negeri Islam. Kedua, pergi dari negeri atau wilayah yang sebagian besar penduduknya ahli bidah. Ketiga, pergi dari negeri atau wilayah yang penuh kezaliman. Keempat, pergi untuk menyelamatkan jiwa. Kelima, menyingkir dari negeri yang tertimpah penyakit menular. Keenam, melarikan diri untuk keselamatan harta dan barang-barang. ${ }^{10}$

${ }^{6}$ Mahmud Yunus, Kamus Arab-Indonesia, cet 9, (Jakarta: Hidakarya Agung, 1990), 477-478.

${ }^{7}$ Muhammad Ibn Mukarram Ibn Manzur, Lisan al-'Arab, juz 9, (Kairo: Dar al-Hadith, 2003), 32.

8 Rohi Baalbaki, Al Mawrid Qamus 'Arabi - Inkilizi Al Mawrid A Modern Arabic-English Dictionary, (Beirut: Dar Al Ilm Li Al Malayin, 2012), 1199.

9 Tim Redaksi Kamus Besar Bahasa Indonesia, Kamus Besar Bahasa Indonesia, (Jakarta: Departemen Pendidikan Nasional, 2008), 523.

${ }^{10}$ Jazuli, Hijrah dalam Pandangan Alquran..., 17. 
Pengertian hijrah dapat pula bermakna "dar al-zulm" menuju "dar al-'adl" dengan tujuan untuk membebaskan agama. Lalu negeri orang-orang adil dapat diartikan sebagai negeri yang dipimpin oleh seorang kafir, namun pemimpin tersebut memberikan jaminan kebebasan dalam menjalankan ibadah sesuai tuntunan agama. Menurut Jazuli, makna hijrah seperti ini banyak didukung oleh ulama Khalaf mengingat banyaknya fenomena yang terjadi. ${ }^{11}$

Mengutip pernyatan Ahzami dalam buku hijrah dalam al-Qur'an atau "alHijrah fi al-Qur'an", hijrah merupakan komponen dari "uslub min asalib ad da'wah" sebuah alat yang dapat digunakan untuk menyelamatkan dan menghindari dari musuh dan pendusta, serta merupakan ranah konflik antara yang baik dan yang buruk. ${ }^{12}$ Sementara menurut Quraish Shihab, bekal yang paling utama di dunia adalah tauhid, sebagaimana tumbuhnya akidah pada manusia dapat diperhatikan dalam peristiwa hijrah Nabi Muhammadh SAW. Dalam hal ini, hijrah menggambarkan sebuah perjuangan untuk menyelamatkan akidah Islam. Bagi Quraish Shihab, hijrah merupakan sebuah perjuangan besar yang diiringi dengan sikap optimisme. ${ }^{13}$

Selanjutnya, al-Faruqi dalam bukunya Hakekat Hijrah mengupas tentang pentingnya peristiwa hijrah yang dialami umat muslim diawal penyerbaran agama Islam. Pada waktu itu, Rasulullah dan pengikutnya mengalamai masa sulit yang di-desak oleh orang-orang kafir, maka mereka hijrah keluar dari kota Makkah. Hal ini menunjukan tingginya nilai-nilai peristiwa hijrah karena Islam dijadikan sebagai pusat hukum ekonomi, hukun sosial, politik dan militer negar. Dengan adanya hijrah, maka terlahirlah sistem yang majemuk dan melahirkan masyarakat yang majemuk pula. ${ }^{14}$

\section{Sejarah Hijrah pada Masa Nabi SAW}

Saat pembahasan mengenai sejarah dari hijrah, maka yang dapat dijadikan contoh ialah peristiwa hijrah Nabi Muhammad SAW. Melihat dari kejadian tersebut dapat dimengerti, bahwa hijrah berkaitan dengan problem keagamaan. Berdasarkan hal tersebut, diketahui bahwa Nabi SAW pernah menyuruh sahabatsahabatnya untuk hijrah ke Habasyah pada tahun $615 \mathrm{M}$, hal tersebut ditujukan agar mendapatkan perlindungan politik bagi kaum Muslim. ${ }^{15}$ Negeri Habasyah dipilih karena terdapat dua sebab. Pertama, berada di tempat yang jauh dari

11 Jazuli, Hijrah dalam Pandangan Alquran ..., 22.

12 Jazuli, Hijrah dalam Pandangan Alquran..., 17.

13 Muhammad Quraish Shihab, Membumikan Al Quran Fungsi dan Peran Wahyu dalam Kehidupan Masyarakat, Cet. ke-12 (Bandung: Mizan, 1996), 291.

14 Ismail Al Faruqi, Hakikat Hijrah: Strategi Dakwah Islam Membangun Tatanan Dunia Baru, terj. Badri Saleh, (Bandung: Mizan, 2004), 27.

${ }^{15}$ Ismail Rajil al-Faruqi, Hakikat Hijrah Strategi Dakwah Islam Membangun Tatanan Dunia Baru, Terj. Badri Saleh, Cet. ke-3, (Bandung: Mizan, 1994), 10. 
Mekkah membuat kaum Quraisy tidak memiliki kontrol terhadap umat Muslim. Kedua, memiliki pemimpin dikenal akan keadilannya.

Berdasarkan pemaparan di atas, maka Nabi SAW memutuskan negeri tersebut menjadi tempat berhijarahnya para sahabat. Kemudian hijrah terjadi kembali tahun $622 \mathrm{M}$ ke Madinah. Kota Madinah dipilih karena berdasarkan lima alasan. Pertama, madinah menrima kedatangan Nabi dengan tangan terbuka. Kedua, penduduk Mekkah yang khawatir terhadap banyaknya yang berhijrah ke Madinah, karena hal tersebut dapat menjadikan jalur perniagaan penduduk Mekkah menuju ke Syam dikuasi oleh umat Muslim. Ketiga, terdapat banyak rintangan yang ada di jalan antar Mekah dan Madinah. Keempat, medan geografis yang sulit dilalui kendaraan karena berada di padang serta sulit untuk mendapatkan. Kelima, keadaan jalan yang belum dapat dipastikan serta keadaan masyarakat Arab yang berada dipadang pasir.

Dari peristiwa hijrah tersebut, dapat dilihat bahwa dalam menentukan target tempat untuk hijrah, Nabi Muhammad telah merencanakan secara matang dengan mencari masyarakat yang dapat menerima Nabi dan kaumnya, melihat letak geografisnya yang jauh dari Mekkah sehingga dapat menghilangkan pengaruh kekuasaan Mekkah terhadap umat Muslim, mencari tempat strategis yang nantinya dapat dijadikan sebagai peluang mata pencaharian umat Muslim, serta melihat politik dan kondisi sosial yang mendukung tegaknya dakwah Nabi Muhammad SAW.

\section{Hukum Hijrah dan Pahala Berhijrah}

Berdasarkan penjelasan sejarah hijrah di atas, akan terlihat ada beberapa hukum hijrah, di antaranya:

1. Hijrah Wajib, yakni perpindahan dari negeri yang darurat menuju negeri yang menegakkan hukum Islam. Hijrah ini diwajibkan karena kondisi yang dialami dalam keadaan darurat.. Berdasarkan penjelasan QS. al-Nisa [4]: 97, dapat dilihat bahwa hijrah dikatakan wajib apabila terdapat dua hal, yaitu memiliki kemampuan untuk berhijrah dan tidak bisa menjalankan ibadah dan kewajiban agama.

2. Hijrah Mandub (sunnah). Hijrah dihukumi mandub apabila berpindah ke negeri kafir namun memiliki perlindungan serta kebebasan menjalankan ibadah. Hijrah yang dilaksanakan oleh manusia memiliki tiga tipe, sebagimana menurut Ibnu Qudamah yang juga dikutip oleh Jazuli. Salah satu di antaranya adalah hijrah ke negeri kafir namun bisa melaksanakan syariat agama tanpa ada gangguan.

3. Hijrah Mubah, yaitu tidak diwajibkan berhijrah bagi orang yang tidak melakukannya. Hijrah mubah ini diberlakukan bagi orang-orang yang tidak sanggup karena lanjut usia, anak kecil, orang sakit, wanita, dan hal lainnya. 
4. Hijrah Haram. Adapun hijrah dihukumi sebagai hijrah haram yaitu apabila berpindah dari negeri Islam menuju ke negeri kafir, hal tersebut bertujuan untuk menolong serta membantu orang-orang kafir.

Tidak dapat dipungkiri bahwa setiap perbuatan baik pasti akan memperoleh balasan yang baik dari Allah. Seperti halnya orang yang melaksanakan hijrah karena Allah, tentu akan ditempatkan derajatnya di tempat yang tinggi dan diberikan pahala baik oleh Allah. Allah berjanji akan memberi beberapa balasan bagi orang yang berhijrah; pertama, di dunia dilimpahkan rezekinya (QS. al-Nisa [4]: 100 dan QS. al-Anfal [7]: 79). Kedua, dihapuskan kesalahan dan diampuni dosa-dosanya (QS. Ali Imran [3]: 195). Ketiga, Allah meninggikan derajatnya (QS. al-Taubah [9]: 20). Keempat, mendapatkan keunggulan atau kemenangan (QS. al-Taubah [9]: 20 dan 100). Kelima, surga menjadi ruang kembali (QS. al-Taubah [9]: 20-22). Keenam, memperoleh rahmat Allah (QS. al-Taubah [9]: 100).

\section{Biografi Singkat Sayyid Quthb dan Tafsir Fi Zhilal Al-Qur'an}

Kampung Musyah, Mesir, merupakan tempat Sayyid Quthb dilahirkan. dibesarkan oleh keluarga yang mencintai al-Qur'an dan mengutamakan ajaran Islam. Sebelum umur 10 tahun, ia sudah bergelar hafidz. Pada tahun 1326 H/1908 M lahir dan tahun 1386 H./1966 M ia wafat. ${ }^{16}$ Sayyid Quthb merupakan seorang ulama besar dari golongan Ikhwanul Muslimin yang brilian yang banyak meninggalkan karya tulisnya. Dia sangat konsisten di dalam agama Islam. Semula dia mendukung Revolusi Mesir dipimpin oleh Najib dan Jamal Abdul Nasser, kemudian setelah sekulerisasi yang drastis dia menentang Nasser, menjadi korban dihukum gantung oleh pemerintah Nasser di tahun 50-an. ${ }^{17}$

Keterlibatannya dalam Ikhwanul Muslimin menyebabkan ia berkenalan dengan penjara. Sayyid Quthb ditahan pertama kali dan kemudian dipenjara tahun 1954. ia dipenjara selama 10 tahun. ${ }^{18}$ Termasuk saat dalam penjara, Sayyid Quthb sangat produktif dalam bidang literasi. Lebih dari 20 buah buku atau karaya yang ditulis oleh Sayyid Quthb. Bakatnya dikembangkan dengan menciptakan buku cerita Nabi Muhammad dan sejarah Islam lainnya untuk anakanak. ${ }^{19}$ Pada masa awal ia menulis, beliau menhasilkan dua buku yakni tentang

\footnotetext{
${ }^{16}$ As-Sayid Muhammad Ali Iyazi, Al Mufassirun: Hayatuhun waman Hajihum wizarah asSaqafah wa al-Irsyad al-Islamy, 512.

17 Mochtar Effendy, Ensiklopedi Agama dan Filsafat, (Palembang: Universitas Sriwijaya, 2001), 73.

18 Ensiklopedi Nasional Indonesia Jilid 14, (Jakarta: Cipta Adi Pustaka, 1989), 12.

19 Van Hoeve, Ensiklopedi Islam, (Jakarta: Ichtiar Baru Van Hoeve, 1993), 146.
} 
keindahan dalam al-Qur'an berjudul "Masyaahidat al-Qiyamah Fil Qur'an" dan "atTaswir al Fanni Fil Qur'an".20

Karya monumentalnya pada tahun 1948 M adalah "Keadilan Sosial dalam Islam (al-Adalah al-Ijtima'iyah Fi'al Islam)." Kemudian diikuti karyanya yang diselesaikan dalam penjara yaitu "Fi Zhilal Al-Qur'an". Selain itu, beberapa karyanya yang lain adalah "Perdamaian Internasional dan Islam" atau "as-Salam al-Alami Wa al-Islam" telah diterjemahkan dalam bahasa Inggris oleh "Muslim Yauth Movement of Malaysia" tahun 1974 menjadi "Islam and Universal Peace" dan diterjemahkan dalam bahasa Indonesia oleh Shalahudin Press Yogyakarta menjadi "Jalan Pembebasan, Rintisan Islam Menuju Perdamaian Dunia." 21 Selain itu, karya lain dari Sayyid Quthb adalah "al-Naqd al-Adabii Usuuluhu wa'Manaahijuhuu, Ma'rakah al Islam war Ra'sumaliyah, Fit Tarikh, Fikrah wa Manahij, al Mustaqbal li Haadzad Diin, Nahw Mujtama' Islami, Ma'rahatuna Ma'al-Yaahuud, al Islam wa Masykilah alHadaarah, Hadza ad-Din dan Khashais at Tashawwur al Islaami wa Muqawwamatuhu dan karya terakhirnya pada masa dalam tahanan yaitu Ma'aalim Fith-Thariq".

Beberapa studi atau kajian yang bersifat keislamam maupun sastra yang ditinggalkan Sayyid Quthb adalah; Muhimmatus Syair Fil Hayah wa Syi'r al Jail alHadhir (1933), Asy-Syathi' al Majhul (Februari 1935), Naqd Kitab "Mustaqbal atsTsaqafah fi Mishr li ad-Duktur Thaha Husain (1939) At-Tashwir Al-Fanni Fil Qur'an (April, 1945), Al-Athyaf-al-Arba'ah, ditulis bersama saudara-saudaranya: Muhammad, Hamidah, dan Aminah (1845), Thifl min Al- Qaryah, tentang gambaran desa serta catatan semasa kecilnya- (1946), Kutub wasyakhsyiyat, sebuah studi Sayyid terhadap karya-karya pengarang lain (1946), Al-Madinah AlManshurah", tentang kisah khayalan semisal kisah Seribu Satu Malam" (1946), Asywak (1947), Masyahid Al- Qiyamah Fil Qur'an, bagian ke dua dari Serial Baru Pustaka al-Qur'an (April, 1947), Raudhatul-Thifl, al-Jadid fi al-Mahfuzhat, AlQashash ad-Diniy, al-Jadid fi al-Lughah al-Arabiyahm, al-Adalah al-Ijtima'iyah Fi al-Islam (April, 1949), Ma'rakah al-Islam wa ar-Ra'samaliyah (Februari, 1951), al-Salam Al-Alami waAl-Islam (Oktober, 1951), Fi Zhiial al-Qur'an (Oktober, 1952), Dirasat Islamiyah (1953), Al-Mustaqbal li-Hadza Ad-Din"; terhitung sebagai pelengkap buku Hadza Ad-Din, Khasha'ish At-Tashawwur Al-Islami wa- Muqawwimatuhu, Al-Islam wa Musykilat Al-Hadharah dan Ma'alim fi At-Thariq.

Selain itu, beberapa studi telah ditulis Sayyid Quthb, yang kemudian beliau tarik dari peredarannya, antara lain: Muhimmah Asy-Sya'ir fi Al-Hayah, Dirasah 'an Syauqi, al-Murahaqah Akhtharuha wa'Ilajuha, Al-Mar'ah Lughz Basith, al-Mar'ah fi Qashash Najib Mahfuzh, Diwan: Ashda'Az-Zaman, Diwan: Al-Ka's Al-Masmumah, Diwan: Qafilah Ar-Raqiq, Diwan: Hulm Al-Fajr, Qisshah Al-Quthath Al-Dhallah,

\footnotetext{
20 Sayyid Quthb, Tafsir fi-zhilal al-Qur'an dibawah Naungan al-Qur'an, Jilid I, 319.
}

21 Van Hoeve, Ensiklopedi Islam..., 146. 
Qisshah min A'maq Al-Wadi, al-Madzahib al-Fanniyah Al-Mu'ashirah, Ash-Shuwar wa Az-Zhilal fi Asy-Syi'r Al-Arabi, al-Qissah fi al-Adab Al-Arabi, Syu'ara' Asy-Syahab, alQissah al-Haditsah, Arabiy Al-Muftara'alaih, Asy-Syarif Ar-Ridha, Lahzat ma'a AlKhalidin, dan Amrika Allati Ra'aitu.

Beberapa karya Sayyid yang sempat dimasukkan dalam bagian Pustaka Baru al-Qur'an, namun akhirnya ditarik lagi adalah: al-Qissah baina At-Taurat wa al-Qur'an, An-Namadij al-Insaniyah fi al-Qur'an, al-Manthiq al-Wijdani fi al-Qur'an dan Asalib al-'Irdh Al-Fanni fi al-Qur'an. sedangkan kajian Sayyid Quthb yang menyebabkannya dieksekusi antara lain: Ma'alim fi At-Thariq, Fi Zhilal As-Sirah, Fi Maukib Al-Iman, Muqawwimat At-Tashawwur Al-Islami, Nahwu Mujtama' Islami Hadza al-Qur'an, Awwaliyyat fi Hadza al-Din dan Tashwibat fi Al-Fikr Al-Islami Al$\mathrm{Mu}$ 'ashir. ${ }^{22}$

Tafsir Fi Zhilal al-Qur'an adalah sebuah tafsir tentang kehidupan di bawah petunjuk Islam dan sinar al-Qur'an. Kitab ini diterima dengan baik oleh orangorang cendekiawan. Karena itu, tidaklah heran jika kitab yang terdiri dari 8 jilid besar ini sudah beberapa kali dicetak ulang. Kitab yang diperlukan oleh umat Islam masa sekarang sebagai kekayaan intelektual sosial. ${ }^{23}$ JJG. Jan Sen berpendapat bahwa tafsir karya Sayyid Qutb yakni “Fi Zhilal Al-Qur'an", terdiri dari tiga jilid, masing-masing jilid berjumlah 200 halaman, hampir tidaklah tafsir al-Qur'an dalam pengertian dan aturan yang erat melekat, akan tetapi lebih cenderung kumpulan besar dari khutbah-khutbah. ${ }^{24}$ Sedangkan Menurut alSayyid Muhammad Ali Iyazi, dilihat dari metodologisnya, tafsir Fi Zhiil Al-Qur'an dapat dimasukkan dalam jenis tahlili. ${ }^{25}$ Dalam pandangan Muhammad Baqir Shadr, metode tahlili atau yang disebut sebagai metode tajzi'i yaitu sebuah teknik yang mencoba menerangkan al-Qur'an dengan rinci, menjelaskan berbagai seginya dan memaparkan apa yang dimaksudkan olehal-Qur'an. ${ }^{26}$

Adapun metode penafsiran Fi Zhilal al-Qur'an dapat diterangkan uraiannya sebagai berikut: Pertama, menetapkan dan membandingkan surat Makiyyah dan Madaniyah yang akan ditafsirkan dilihat dari segi topik yang akan dibahas dan karakteristiknya. Kedua, menjelaskan munasabah surat dengan surat sebelumnya. Ketiga, pada awal setiap surat menerangkan masalah tentang pengertian surat yaitu untuk mengenalkan tema mendasar pada surat tersebut. Keempat, menerangkan asbab al-nuzul-nya. Kelima, menjelaskan makna yang terkandung

22 Shalah Abdul Fatah al-Khalidi, Pengantar Memahami Tafsir fi-zhilal al-Qur'an Sayyid Quthb, (Surakarta: Era Intermedia, 2001), 41-43.

${ }^{23}$ Manna' Khalil al-Qattan, Mabahits fi Ulumul Qur'an.., 514-515.

${ }^{24}$ JJG. Jansen, The Interpretation of the Koran in Modern Egypt, (E.J.Brdl, Leiden, 1980), 79.

${ }^{25}$ Ali Iyazi, Al Mufassirun: Hayatuhun waman Hajihum..., 515.

${ }^{26}$ Mohammad Nor Ichwan, Belajar Mudah Ilmu-ilmual-Qur'an, IAIN Walisongo Semarang, 2001, 266 . 
ataupun menjelaskan secara fasih maksud dari ayat tersebut secara umum. Keenam, waspada terhadap cerita-cerita israiliyat dan menjauhkan penafsiran dari ketidak samaan fiqh-nya, serta memiliki fokus dalam membahas masalah kalam, filsafat, ataupun bahasa. ${ }^{27}$

Jika dilihat dari coraknya, Tafsir Fi Zhilal Qur'an dapat dimasukkan dalam golongan Tafsir al-Adabi Ijtima'i, yaitu jenis penafsiran Qur'an yang menerangkan secara cermat dengan mengutamakan tujuan diturunkannya al-Qur'an dan selanjutnya menerapkannya kepada masyarakat sebagai solusi dari permasalahan umat Islam dan bangsa seiring dengan perkembangan umat masa ini. ${ }^{28}$ Dalam corak penafsirannya, Quthb menggunakan beberapa pendekatan, sebagaimana yang diungkapkan oleh Shalah Abdul Fattah, bahwa dalam tafsirnya Quthb melewati tiga metodologi (manhaj), yakni metodologi keindahan bahasa (al-manhaj al-jamali), metodologi pemikiran (al-manhaj al-fikri), dan metodologi pergerakan (al-manhaj haraki).

\section{Makna Hijrah Menurut Sayyid Quthb}

Mengenai pembahasan tentang makna hijrah, Sayyid Qutub memberi beberapa arti, antara lain: hijrah dapat berarti "dar al-kufr wa al-harbi" yaitu berpindah dari tempat non-Muslim (kafir) atau tempat dalam kondisi genting mengarah ke negeri Islam atau (Dar al-Islam). Dar al-Kufr yang dimaksud ialah negeri yang dikuasai oleh orang-orang kafir yang menegakkan hukum-hukum kafir. Dalam hal ini, negeri kafir terbagi menjadi dua bagian yakni negeri yang memerangi kaum Muslim dan menjaga kaum Muslim. Sedangkan "Dar al-Islam" atau negeri Islam yaitu negeri yang menegakkan hukum syariat Islam dan dikuasai oleh orang Islam meskipun masyarakat di negeri tersebut didominasi oleh orang-orang non-Muslim.

Menurut Sayyid Quthb, makna hijrah bisa dikembangkan lagi dengan enam macam, yaitu: pertama, pergi dari negeri atau wilayah yang dzalim menuju negeri Islam. Kedua, pergi dari tempat mayoritas penduduknya ahli bid'ah. Ketiga, pergi dari negeri atau wilayah yang banyak mudharatnya. Keempat, meninggalkan tempat untuk menyelamatkan jiwa. Kelima, menyingkir dari negeri atau wilayah yang terkena wabah penyakit. Keenam, melarikan diri untuk keselamatan harta dan barang-barang. ${ }^{29}$

Pendapat di atas dapat diketahui bahwa Sayyid Qutub telah memperluas makna hijrah. Ia menegaskan bahwa hijrah dapat pula dimaksudkan sebagai perjalanan untuk mencari pelajaran dan hikmah. Dapat juga bermakna

27 Ali Iyazi, Al Mufassirun: Hayatuhun waman Hajihum..., 515.

${ }^{28}$ M. Husein adz-Dzahabi, At-Tafsir wa al Mufassirun, (T.tp: Dar al-Kutub al-Hadisah, 1976), 547.

29 Jazuli, Hijrah dalam Pandangan Alquran..., 17. 
meninggalkan tempatnya untuk mencari penghidupan yang baik dengan cara bekerja dan berdagang mengharapkan ridha Allah SWT, membela tanah air, menuntut ilmu serta mengunjungi tempat yang diberkahi Allah seperti dua tanah suci dan Masjid al-Aqsa.

\section{Karakteristik Hijrah Menurut Sayyid Qutub dalam Tafsir Fi Zhilal Al-Qur'an}

Penggunaan kata hijrah menurut Sayyid Qutub dalam tafsir Fi Zhilal alQur'an memiliki tiga pengertian. ${ }^{30}$ Pertama, hijrah secara fisik, yakni meninggalkan satu tempat menuju tampat lain yang bersifat fisik, atau disebut juga sisi hisi/haraki. Maksudnya makna hijrah memiliki arti seperti pengertiam hijrah yang sesungguhnya yakni berpindah atau meninggalkan tempat menuju ke wilayah lain untuk menetap (secara fisik) serta sesuai dengan pedoaman Rasulullah SAW, ${ }^{31}$ seperti penjelasan dalam QS. al-Anfal [7]: 72. Kedua, Hijrah dengan pindah secara psikis meskipun tetap berdekatan secara fisik, seperti diungkapkan dalam QS. al-Muzzammil [73]: 10, dan ketiga, hijrah dalam arti pemindahan secara spiritual.

Sayyid Qutub menjelaskan dalam karyanya yaitu tafsir Fi Zhilal al-Qur'an, kata hijrah tersusun dari beberapa huruf yakni ha, ja dan ra dengan bermacam derivasinya disebut dalam al-Qur'an berulang sebanyak 31 kali yang terdapat dalam 15 surah dan 27 ayat. ${ }^{32}$ Ayat-ayat hijrah yang berarti "meninggalkan" (hijrah secara fisik) disebutkan sebanyak 21 ayat, terdapat dalam beberapa surat dalam al-Qur'an, yaitu: QS. al-Baqarah [2]: 218, QS. al-Anfal [7]: 72, 74, 75, QS. alNur [24]: 22, QS. Ali Imran [3]: 195, QS. al-Muddatsir [74]: 5, QS. al-Nisa [4]: 34, 89, 97, dan 100, QS. al-Taubah [9]: 20, QS. al-Nahl [16]: 41, QS. al-'Ankabut [29]: 26, QS. al-Muzzammil [73]: 10, QS. al-Mumtahanah [60]: 10, QS. Maryam [19]: 46, QS. al-Mu'minun [23]; 67, QS. al-Hasyr [59]: 8-9, dan QS. al-Ahzab [33]: 6 dan 50. Selain itu, ayat-ayat hijrah yang bermakna secara non-fisik terdapat dalam enam surat, yaitu: QS. al-Nisa [4]: 34, QS. Maryam [19]: 46, QS. al-Furqan [25]: 20, QS. alMu'minun [23]: 67, QS. al-Muzzammil [73]: 10, dan QS. al-Muddatsir [74]: 5.

Dilihat dari beberapa ayat yang tercantum di atas, selanjutnya dapat disimpulkan bahwa kata hijrah terbagi menjadi dua kelompok, yaitu hijrah secara-fisik dan hijrah psikis (non-fisik). Hijrah secara fisik ialah berpindah ke tempat lain yang bersifat fisik atau nyata, atau disebut juga sisi hararki. Adapun ayat-ayat yang berkitan dengan hijrah secara fisik disebutkan dalam 21 ayat dengan berbagai derivasinya. Dalam ayat-ayat tersebut, terdapat makna dan

30 Jazuli, Hijrah dalam Pandangan Alquran..., 17. t.th, 42 .

31 Muhammad Ibrahim Abd-Rahman, al-Hijrah wa al-Muhajirun fi al-Qur'an wa al-Sunnah,

32 Muhammad Fu'ad Abd al-Baqi, al-Mu'jam Mufahras li Alfadz al-Qur'an al-Karim, (Indonesia: Maktab Dahlan, t.th), h. 900-901. 
unsur hukum yang di dalamnya memuat dua poin, yakni: Aaat hijrah yang memuat unsur aqidah dan ayat hijrah yang mengandung unsur hokum. Sebaliknya, kelompok hijrah secara non-fisik sangat berbeda dengan hijrah dalam bentuk fisik, kelompok hijrah ini perubahan perilaku, sifat, tabiat dan kebiasaan.

\section{Kontribusi Penerapan Hijrah Sayyid Qutub Pada Masa Sekarang}

Hijrah pada masa sekarang tidak sama dengan migrasi, karena hijrah pada masa sekarang menjadikan iman kepada Allah sebagai landasan utamanya, hijrah dijadikan sebagai tolak ukur keimanan dalam diri seseorang. Dilihat dari segi bahasa, maka dapat diketahui keterkaitan antara hijrah dengan migrasi. Terdapattitik temu antara hijrah dengan migrasi, yakni berpindah dari satu daerah atau wilyah ke wilayah lain. Hijrah dapat bermakna sebagai perpindahan atau meninggalkan suatu wilayah menuju ke tempat lain, sedangkan migrasi dapat diartikan sebagai menetap pada daerah (negara) yang baru dan meninggalkan daerah (negara) sebelumnya. ${ }^{33}$

Dalam menyikapi hal ini, makna hijrah lebih cenderung berdasarkan pendapat Rohi Ba'albaki yang menyatakan bahwa hijrah berarti "to Migrate" yaitu melakukan migrasi. Sedangkan pendapat Ibn Mandzur dalan kamus "Lisan al'Arab" menyatakan, bahwa hijrah adalah meninggalkan satu tempat menuju ke tempat lain. ${ }^{34}$ Selain mengacu kepada pengertian secara etimologi, terdapat pula pemaknaan hijrah secara lebih luas sebagaimana yang dijelaskan oleh Ibn 'Arabi. Sehingga dalam kaitannya dengan migrasi penulis cenderung kepada pendapat Ibn 'Arabi yang lebih mendekati makna migrasi. ${ }^{35}$

Ada pun jenis hijrah yang dapat dilakukan pada masa sekarang menurut pendapat Sayyid Qutub sebagai berikut:36 (1) Berpergian untuk mengambil hikmah dan pelajaran tertentu; (2) Berpergian untuk melakukan ibadah haji; (3) Berpergian untuk keperluan jihad; (4) Berpergian untuk bekerja; (5) Berpergian dalam rangka menuntut ilmu; (6) Mendatangi tempatyang dimuliakan Allah; dan (7) Silaturahmi pada saudara-saudara yang berjuang di jalan Allah.

Berdasarkan jenis hijrah yang tertera di atas, maka bisa diketahui bahwa ada keterkaitan makna hijrah yang diutarakan oleh Sayyid Quthb dengan ayat alQur'an, yaitu pada poin pertama diketahui hijrah adalah perjalanan mencari hikmah atau pelajaran. Selain itu. pembahasan mengenai perjalanan (berpergian)

${ }^{33}$ Goldthrope, J. E. Sosiologi Dunia Ketiga Kesenjangan dan Pembangunan. terj.Sukadijo. edisi 2. (Jakarta: Gramedia Pustaka Utama, 1992), 43.

34 Muhammad Abdullah al-Khathib, Makna Hijrah Dulu dan Sekarang, (Jakarta: Gema Insani Press, 1996 M), Cet. ke-1, 56.

35 Jazuli, Hijrah dalam Pandangan Alquran..., 43.

7.

36 Umar Sulaiman Al-Asyqar, Fiqih Niat, terj. Faisal Saleh, (Jakarta: Gema Insani Press, 2006), 
dalam rangka mencari rezeki baik bekerja maupun berbisnis termasuk bagian dari hijrah. Selanjutnya, dari sudut pandang sosial dapat diketahui bahwa terdapat keterkaitan antara hijrah dengan migrasi. ${ }^{37}$

\section{PENUTUP}

Dari penjelasan di atas, dapat disimpulkan bahwa makna hijrah menurut Sayyid Qutub mengandung berbagai arti, antara lain: hijrah dalam arti berpindah atau meninggalkan negeri yang mayoritas ahli bid'ah dan orang-orang kafir, meninggalkan negeri atau tempat yang dipenuhi oleh hal yang merugikan baik itu demi keselamatan jiwa, kesehatan tubuh agar terhindar dari penyakit, dan melarikan diri untuk menyelamatkan harta benda. Sayyid Quthb juga memberi tiga karakteristik hijrah dalam tafsirnya, yaitu: hijrah secara fisik, hijrah dengan pemisahan psikis (sungguhpun secara fisik masih berdekatan), dan hijrah dalam arti pemisah secara spiritual. Sedangkan jenis hijrah yang bisa dilakukan pada masa sekarang menurut Sayyid Qutub antara lain: menempuh pendidikan (menuntut ilmu), perjalanan untuk menegakkan agama Allah (jihad) dan membela negara, serta perjalanan untuk menjemput rezeki.

\section{DAFTAR PUSTAKA}

Abd-Rahman, Muhammad Ibrahim. al-Hijrah wa al-Muhajirun fi al-Qur'an wa alSunnah, t.th.

Adhim, Muhammad Abdul. Strategi Hijrah Prinsip-Prinsip Ilmiah dan llham Tuhan, terj. M. Masnur Hamzah. Solo: Tiga Serangkai. 2004

adz-Dzahabi, M. Husein, At-Tafsir wa al-Mufassirun, T.tp: Dar al-Kutub al-Hadisah, 1976.

Al-Asyqar, Umar Sulaiman. Fiqih Niat, terj. Faisal Saleh. Jakarta: Gema Insani Ptess, 2006.

al-Baqi, Muhammad Fu'ad Abd. al-Mu'jam Mufahras li Alfadz al-Qur'an al-Karim. Indonesia: Maktab Dahlan, t.th

Alfaruqi, Ismail. Hakikat Hijrah: Strategi Dakwah Islam Membangun Tatanan Dunia Baru, terj. Badri Saleh. Bandung: Mizan, 2004.

al-Khalidi, Shalah Abdul Fatah. Pengantar Memahami Tafsir fi-zhilal al-Qur'an Sayyid Quthb. Surakarta: Era Intermedia. 2001

Aliy Iyaziy, As-Sayid Muhammad. Al Mufassirun: Hayatuhun waman Hajihum wizarah as-Saqafah wa-al-Irsyad al-Islamy.

al-Khathib, Muhammad Abdullah. Makna Hijrah Dulu dan Sekarang. Jakarta: Gema Insani Press. 1996.

37 Abu Faris, Hijrah Nabawi Menuju Komunitas Muslim, (T.tp: Citra Islami Press, 1997), 75. 
Baalbaki, Rohi. Al Mawrid Qamus-'Arabi Inkilizi Al-Mawrid A Modern ArabicEnglish Dictionary. Beirut: Dar Al-Ilm Li Al-Malayin. 2012.

Effendy, Mochtar. Ensiklopedi Agama dan Filsafat. Palembang: UniversitasSriwijaya, 2001.

Faris, Abu. Hijrah Nabawi MenujuKomunitas Muslim. t.tp: Citra Islami Press. 1997.

Goldthrope, J. E. Sosiologi Dunia Ketiga Kesenjangan dan Pembangunan. terj. Sukadijo. edisi 2. Jakarta: Gramedia Pustaka Utama.1992.

Hamka. Tafsir Al-Azhar. Jakarta: Pustaka Panjimas. 1984.

Hoeve, Van. Ensiklopedi Islam. Jakarta: Ichtiar Baru Van Hoeve. 1993.

Horton, Paul B, ChesterL. Hunt. Sosiologi Jilid Dua, terj. Aminuddin Ram, cet 3. Jakarta: Erlangga, 1992.

Ibn Manzur, Muhammad Ibn-Mukarram. Lisan al-'Arab. juz 9. Kairo: Dar alHadith, 2003.

Ichwan, Mohammad Nor. Belajar Mudah Ilmu-ilmu al-Qur'an, IAIN Walisongo Fakultas Ushuluddin, Semarang. 2001.

Jansen, JJG. The Interpretation of the Koran in Modern Egypt. E.J.Brdl, Leiden. 1980.

Jazuli, Ahzami Sami'un. Hijrah dalam Pandangan Al-Quran, terj. Eko Yulianti. Jakarta: Gema InsaniPress. 2006.

Poerwadiningrat. Kamus Besar Bahasa Indonesia, Edisi 3. Jakarta: Balai Pustaka, 2005.

Quthb, Sayyid. Tafsir fi-zhilal al-Qur'an di bawah Naungan al-Qur'an, Jilid I, terj...,

Ridha, M. Rasyid. Tafsir Al-Quran Al Hakim Al Syahir Bi Tafsir Al-Manar, Juz 5 Beirut: Dar Al Fikr, 2007.

Shihab, Muhammad Quraish. Membumikan Al-Quran; Fungsi dan Peran Wahyu dalam Kehidupan Masyarakat, Cet ke-12. Bandung: Mizan. 1996.

TimRedaksi Kamus Besar Bahasa Indonesia, Kamus Besar Bahasa Indonesia. Jakarta: Departemen Pendidikan Nasional. 2008.

Yunus, Mahmud. Kamus Arab-Indonesia. cet 9. Jakarta: Hidakarya Agung. 1990. 